Technological University Dublin

DÜBLIN

ARROW@TU Dublin

2017-6

\title{
Lack of Effect of Vitamin D3 Supplementation in Autism: a 20-week, Placebo-Controlled RCT
}

\author{
Conor Kerley \\ Technological University Dublin, conor.kerley@gmail.com \\ Clare Power \\ Louise Gallagher
}

See next page for additional authors

Follow this and additional works at: https://arrow.tudublin.ie/scschbioart

Part of the Medical Immunology Commons

\section{Recommended Citation}

Kerley CP, Power C, Gallagher L, Coghlan D. (2017) Archives of disease in childhood, [16 Jun 2017, 102(11):1030-1036] doi: 10.1136/archdischild-2017-312783. Epub 2017 Jun 16.

This Article is brought to you for free and open access by the School of Biological Sciences at ARROW@TU Dublin. It has been accepted for inclusion in Articles by an authorized administrator of ARROW@TU Dublin. For more information, please contact arrow.admin@tudublin.ie, aisling.coyne@tudublin.ie,gerard.connolly@tudublin.ie.

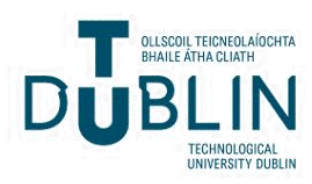




\section{Authors}

Conor Kerley, Clare Power, Louise Gallagher, and David Coghlan

This article is available at ARROW@TU Dublin: https://arrow.tudublin.ie/scschbioart/168 


\title{
Lack of effect of vitamin $D_{3}$ supplementation in autism: a 20-week, placebo-controlled RCT
}

\author{
Conor P Kerley, ${ }_{1}^{1}$ Clare Power, ${ }_{1}^{1}$ Louise Gallagher, ${ }^{2,3}$ David Coghlan ${ }^{1}$
}

'Department of Paediatric Medicine, National Children's Hospital, Dublin, Ireland ${ }^{2}$ Department of Psychiatry, Trinity College Dublin, Dublin, Ireland

${ }^{3}$ Trinity Translational Medicine Institute, St. James's Hospital, Dublin, Ireland

\section{Correspondence to}

Dr Conor P Kerley, Department of Paediatric Medicine, Nationa Children's Hospital, Tallaght, Dublin 24, Ireland; conorkerley@gmail.com

Received 27 January 2017 Revised 4 May 2017 Accepted 5 May 2017

\section{CrossMark}

To cite: Kerley CP, Power C,
Gallagher L,
et al. Arch Dis Child Published
Online First: [please include
Day Month Year].
doi:10.1136/
archdischild-2017-312783

\section{ABSTRACT}

Objectives Data suggest a potential role for vitamin D in autism spectrum disorder (ASD). We wanted to assess the effect of vitamin $D_{3}$ supplementation compared with placebo in children with ASD.

Design This was a double-blind, randomised, placebocontrolled trial.

Setting A paediatric outpatient centre at high latitude over the winter season in Dublin, Ireland $\left(53^{\circ} \mathrm{N}\right)$.

Patients 42 children with ASD.

Interventions $2000 \mathrm{IU}$ vitamin $\mathrm{D}_{3}$ supplementation or placebo daily for 20 weeks.

Main outcome measures Assessments were completed at baseline and after 20 weeks of supplementation. The primary outcome was the stereotypic behaviour subscale from the Aberrant Behaviour Checklist (ABC). Secondary exploratory outcomes included additional subscales from the $A B C$, the Social Responsiveness Scale and rating on the Developmental Disabilities_Children's Global Assessment Scale (DD-CGAS) as well as biochemical parameters of total vitamin $D$ status (25-hydroxyvitamin $\mathrm{D}(25(\mathrm{OH}) \mathrm{D}))$, immunity and systemic inflammation. Results 38 children completed the trial. Baseline $25(\mathrm{OH}) \mathrm{D}$ was $54.2 \pm 19.7 \mathrm{nmol} / \mathrm{L}$. Following vitamin $\mathrm{D}_{3}$ supplementation, there was a significant increase in $25(\mathrm{OH}) \mathrm{D}$ to $83.8 \mathrm{nmol} / \mathrm{L}(\mathrm{p}=0.0016)$ but no effect on the primary endpoint. However, there was an improvement in self-care on DD-CGAS ( $p=0.02)$. In contrast, there was also a trend toward decreased inappropriate speech in the placebo group $(p=0.08)$.

Conclusion Vitamin D supplementation had no effect on the primary outcome with limited and inconsistent effects in children with ASD. Considering the other promising data as well as the relative safety and cheapness of vitamin D supplementation, further trials are warranted.

Trial registration NCT02508922.

\section{INTRODUCTION}

Autism spectrum disorder (ASD), a complex, heterogeneous neurodevelopmental disorder, has an estimated prevalence of $\sim 1 \%$ in children. ASD is associated with significant genetic risk factors. However, the impact of environmental factors cannot be discounted. Indeed, epigenetic mechanisms have been implicated suggesting that geneenvironment interactions are important in mediating risk. ${ }^{12}$

One potential environmental risk factor for ASD is vitamin D deficiency (VDD) which affects $\sim 1$ billion people. ${ }^{3}$ While VDD has detrimental effects on bone health, recent reports

\section{What is already known on this topic?}

- Autistic children are at risk for low vitamin D intakes and status.

- Vitamin D is hypothesised to have neurological immunomodulatory and anti-inflammatory roles, which may be relevant in autism.

- Recent animal model and open-label studies as well as a double-blind, randomised, placebocontrolled trial suggest benefit of vitamin D supplementation.

\section{What this study adds?}

- We present one of first randomised controlled trials of vitamin D supplementation in autism.

- Vitamin D status increased significantly, but there was no effect on stereotypical behaviour as assessed with Aberrant Behaviour Checklist (primary endpoint).

- We did observe some benefits, but this was inconsistent and further trials are recommended.

suggest implications for neurological, immune and inflammatory disorders due to its unique role in brain homeostasis, neurodevelopmental and immunological modulation and gene regulation. ${ }^{4-7}$

Multiple studies have noted inadequate vitamin $D$ intake ${ }^{8-11}$ and/or status ${ }^{11-21}$ in children with ASD. Indeed, a 2016 meta-analysis of 11 studies, including 870 ASD children and 782 typically developing children, demonstrated significantly lower 25 -hydroxyvitamin D $(25(\mathrm{OH}) \mathrm{D})$ in ASD compared with controls. ${ }^{22}$

Recent reviews have detailed the associations between vitamin D and ASD. ${ }^{4-7} 23$ VDD has been implicated in the development of ASD symptoms in an animal model..$^{24}$ Low-level evidence based on a single case report ${ }^{25}$ and two open-label studies support the role of vitamin D supplementation in ASD. ${ }^{26} 27$ Additionally, a single, double-blind, randomised, placebo-controlled trial reported benefit of supplementation in ASD. ${ }^{28}$ However, any potential mechanisms mediating a positive effect of vitamin D supplementation in ASD remain obscure. Therefore, we wanted to rigorously assess the effects of vitamin $\mathrm{D}_{3}$ supplementation in ASD.

\section{METHODS}

This trial was conducted at the National Children's Hospital (Dublin, Ireland) following institutional 
review board approval. At baseline, trial information was provided, and written parental/guardian consent was obtained prior to study procedures.

\section{Subjects}

ASD children were recruited from paediatric neurodevelopmental and general outpatient clinics as well as through community ASD services. Inclusion criteria included clinician-diagnosed ASD (by either Autism Diagnostic Observation Schedule, Diagnostic and Statistical Manual of Mental Disorders or Diagnostic Instrument for Social and Communication Disorders), Social Communication Questionnaire (SCQ) score $>15$, aged $<18$ years and medically stable. Exclusion criteria included non-definitive ASD diagnosis, conditions/medications that influence vitamin D metabolism or absorption (including epilepsy), vitamin A supplementation (including cod liver oil) and chronic, non-autistic medical issues.

\section{Supplements}

At baseline, each parent/guardian was provided with eight bottles of drops containing either vitamin $\mathrm{D}_{3}$ or identical placebo in a double-blind, randomised, age and gender balanced ratio. A physician not involved in data gathering (DC) generated the allocation sequence, while a nutrition researcher enrolled subjects (CPK). Parents/guardians were instructed to administer 20 drops daily for 20 weeks to their child with food (2000 IU).
Diet, supplement use and particularly exposure to ultraviolet $\mathrm{B}$ radiation contribute to vitamin $\mathrm{D}$ status. Therefore, we conducted this trial at high latitude $\left(53^{\circ} \mathrm{N}\right)$ during winter season when skin vitamin D synthesis is minimal. Further, we advised recruits not to change dietary/supplemental behaviours during the trial. We assessed behaviour relating to vitamin D status with the VIDSun questionnaire at baseline and endpoint. ${ }^{29}$ Supplement compliance was assessed with a diary and by returning the bottles of drops at the follow-up visit.

\section{Study design}

This was a parallel, randomised, double-blind, placebo-controlled trial and involved two clinic visits (figure 1). Recruitment occurred between September and December 2015, with follow-up 20 weeks later. All assessments were conducted at baseline and follow-up. Following completion of day 1 presupplementation assessments, subjects were randomised to vitamin $\mathrm{D}_{3}\left(\mathrm{D}_{3}\right)$ or placebo $(\mathrm{PL})$ groups using an online randomisation programme.

\section{Assessments}

We used a combination of commonly used parental and clinician subjective autistic measures and biochemical indices.

\section{Aberrant Behaviour Checklist (ABC)}

The $\mathrm{ABC}$, a 58-item informant (eg, parent) rating scale, includes five subscales: irritability, lethargy/social withdrawal,

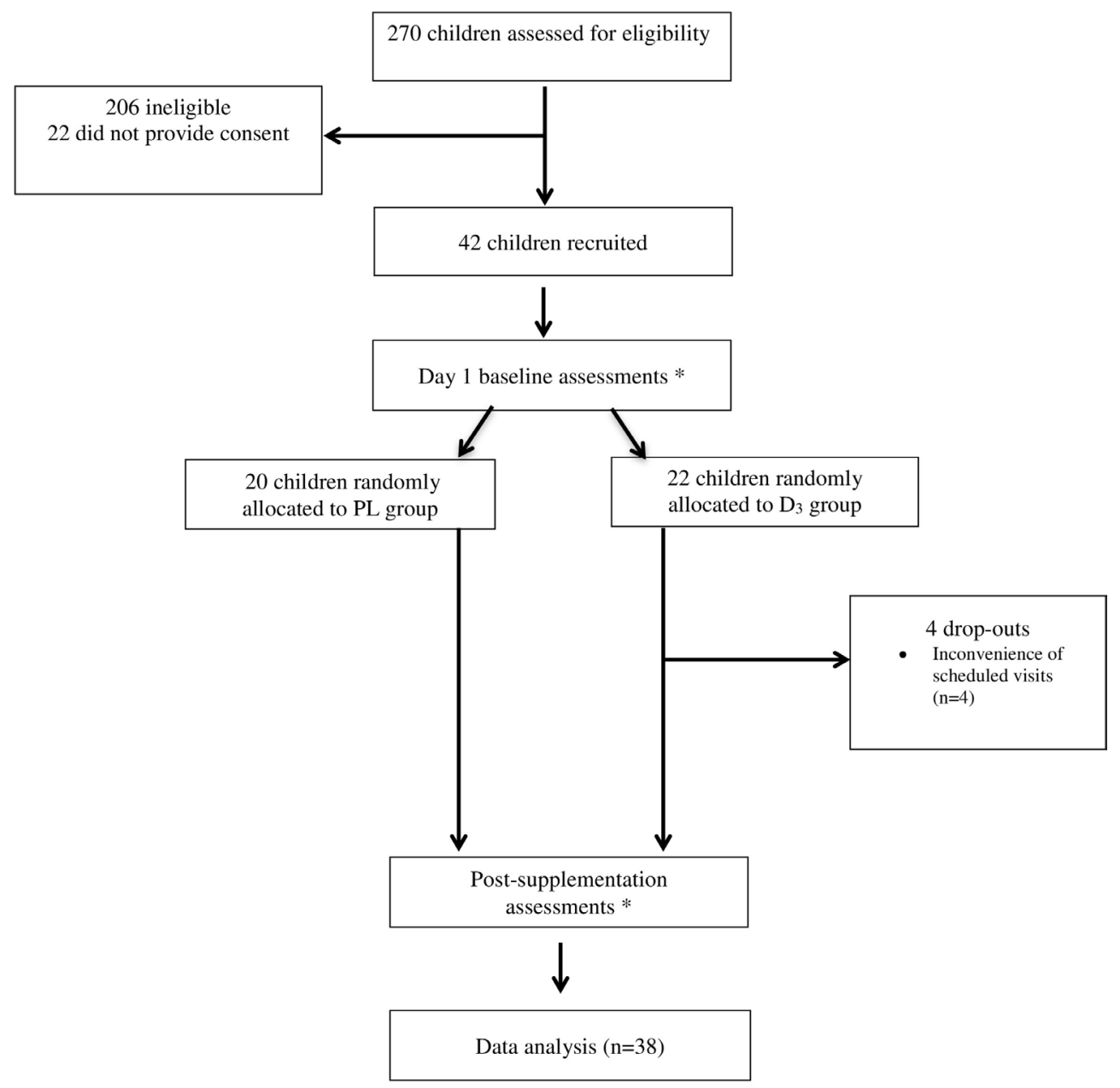

Figure 1 Trial design. *Assessments included subjective autism spectrum disorder measures and blood draw. D3, vitamin $\mathrm{D}_{3}$; PL, placebo. 
stereotypical behaviour, hyperactivity/non-compliance and inappropriate speech. Higher scores indicate greater severity of problem behaviours. ABC is clinically relevant, is sensitive to change, was designed to measure treatment effects and has been used extensively in ASD. ${ }^{30}$ Therefore, we selected the stereotypical behaviour subscale of the $\mathrm{ABC}$ as our primary endpoint.

The Social Responsiveness Scale (SRS)

SRS is another clinically relevant, commonly used, informant rating scale in ASD research.

\section{The Developmental Disabilities—Children's Global Assessment Scale (DD-CGAS)}

DD-CGAS is a clinician-rated instrument designed to estimate global functioning of the child during the past month across all domains of functioning (self-care, communication, social behaviour and academic functioning).

\section{Biochemistry}

Venous blood samples were collected at baseline and endpoint and analysed locally for complete blood count, 25(OH)D and $\mathrm{C}$ reactive protein (CRP), as well as renal, liver and bone profiles.

We assessed vitamin D status by measuring total serum $25(\mathrm{OH})$ D. The rationale for measuring $25(\mathrm{OH}) \mathrm{D}$ and the methods have been described previously. ${ }^{31}$ We dichotomised 25(OH)D levels based the most recent Institute of Medicine (IOM) recommendations where $<50 \mathrm{nmol} / \mathrm{L}$ indicates VDD and $>50 \mathrm{nmol} / \mathrm{L}$ indicates vitamin D sufficiency (VDS). ${ }^{32}$

\section{Statistics}

For this trial, the stereotypical behaviour subscale from $A B C$ served as the primary outpoint. We calculated that a sample size of 34 (17 to each group) would provide $81 \%$ power at the 0.05 significance level based on an SD of $5.61^{26}$ to detect a treatment difference $5.7 .^{26}$ We factored in a drop-out rate of $15 \%$ and therefore recruited 42 ASD subjects. All data were normally distributed results and expressed as mean $\pm S D$. Paired t-tests were used to assess differences within groups between variables, while unpaired t-tests were used to assess differences between groups. Pearson's coefficient was used for correlation analysis. $\mathrm{p}<0.05$ was considered statistically significant. Statistical analysis was performed using a software package (SPSS, version 18).

\section{RESULTS}

We screened 270 children for eligibility. Of these, 64 children were eligible, but only 42 children provided consent, were recruited and completed baseline assessments (figure 1).

\section{Baseline findings}

All 42 recruited children completed all baseline measures (38 male, mean age 7.1 years; mean body mass index (BMI) $17.6 \mathrm{~kg} /$ $\mathrm{m}^{2}$ ). Mean 25(OH)D was $54.2 \mathrm{nmol} / \mathrm{L}$ (range: $15-101 \mathrm{nmol} / \mathrm{L}$ ). According to the IOM guidelines, 17 children were VDD (40\%), while 25 were VDS. There were no significant differences in demographics (age and BMI) or serum biomarkers between the VDD and VDS groups.

Using balanced randomisation, children assigned to placebo were well matched to those assigned to vitamin $\mathrm{D}_{3}$. However, there were trends toward higher lethargy scores in the $\mathrm{D}_{3}$ group but lower scores for inappropriate speech and social behaviour.

\begin{tabular}{|c|c|c|c|}
\hline & Placebo & Vitamin D & p Value* \\
\hline $\mathrm{n}$ & 20 & 18 & \\
\hline Age (years) & $6.9 \pm 3.8$ & $7.9 \pm 23.4$ & 0.41 \\
\hline Male, n (\%) & $18(90)$ & $15(83)$ & - \\
\hline BMI $\left(\mathrm{kg} / \mathrm{m}^{2}\right)$ & $17.7 \pm 3.9$ & $18.1 \pm 2.9$ & 0.69 \\
\hline SCQ & $20.2 \pm 3.8$ & $19.6 \pm 3.1$ & 0.76 \\
\hline \multicolumn{4}{|l|}{$A B C$} \\
\hline Irritability & $14.1 \pm 10.8$ & $14.8 \pm 10.8$ & 0.81 \\
\hline Lethargy & $10.2 \pm 6.3$ & $13.4 \pm 7.5$ & 0.08 \\
\hline Stereotypy & $7.8 \pm 5.2$ & $6.7 \pm 4.4$ & 0.5 \\
\hline Hyperactivity & $18.6 \pm 11.9$ & $19.1 \pm 7.9$ & 0.86 \\
\hline $\begin{array}{l}\text { Inappropriate } \\
\text { speech }\end{array}$ & $5.4 \pm 3.8$ & $4.2 \pm 2.2$ & 0.3 \\
\hline Total & $55.9 \pm 32.8$ & $58.3 \pm 21.5$ & 0.78 \\
\hline \multicolumn{4}{|l|}{ SRS } \\
\hline Total & $150 \pm 25.2$ & $149.1 \pm 27.2$ & 0.89 \\
\hline \multicolumn{4}{|l|}{ DD-CGAS } \\
\hline Self-care & $47 \pm 19.1$ & $39.1 \pm 20.92$ & 0.24 \\
\hline Communication & $46.5 \pm 17.3$ & $40.9 \pm 18$ & 0.34 \\
\hline Social behaviour & $50.5 \pm 15.7$ & $42.6 \pm 16.4$ & 0.15 \\
\hline School/academic & $46.5 \pm 17.6$ & $43.2 \pm 22.9$ & 0.63 \\
\hline \multicolumn{4}{|c|}{ Biochemistry } \\
\hline CRP (mg/L) & $2.7 \pm 5.7$ & $1.1 \pm 0.4$ & 0.27 \\
\hline $\mathrm{Ca}^{2+}(\mathrm{mmol} / \mathrm{L})$ & $2.3 \pm 0.06$ & $2.33 \pm 0.07$ & 0.36 \\
\hline 25(OH)D (nmol/L) & $51.7 \pm 19.8$ & $58.4 \pm 17.9$ & 0.3 \\
\hline
\end{tabular}

${ }^{*} \mathrm{p}$ Values were derived using two-tailed, independent-samples t-tests. 25(OH)D, 25-hydroxyvitamin D; ABC, Aberrant Behaviour Checklist; BMI, body mass index; $\mathrm{Ca}^{2+}$, albumin-corrected calcium; CRP, C reactive protein; DD-CGAS, Developmental Disabilities—Children's Global Assessment Scale; SRS, Social Responsiveness Scale.

\section{Follow-up results}

Of the 42 recruits, four children dropped out due to inconvenience of scheduled visits (figure 1) (all from the vitamin $\mathrm{D}_{3}$ group). Therefore, 38 children completed the trial (table 1).

Compliance with trial supplements was high in both groups $(>95 \%)$ as assessed with a diary and by examining the bottles of drops at follow-up. No adverse effects were reported.

Table 2 displays a comparison of changes in means after 20 weeks. As expected, after 20 weeks of vitamin $\mathrm{D}_{3}$ supplementation, there was a significant increase in $25(\mathrm{OH}) \mathrm{D}$ compared with PL $(p=0.0016)$, but no change in VIDSun score in either group. No effect was observed on the primary endpoint (stereotypical behaviour subscale of the $\mathrm{ABC}$ ). A significant improvement was observed in self-care score on DD-CGAS in $\mathrm{D}_{3}$ versus $\mathrm{PL}(\mathrm{p}=0.02)$. A non-significant decrease in inappropriate speech was observed in PL versus $D_{3}(p=0.08)$. No other significant between group differences were observed for the behavioural measurements.

$25(\mathrm{OH}) \mathrm{D}$ decreased in a single child in the vitamin D supplementation arm $(-9 \mathrm{nmol} / \mathrm{L})$ and did not change in a second child. Furthermore, 25(OH)D did not change in two children and actually increased in nine children in the PL group $(+1$ to $+45 \mathrm{nmol} / \mathrm{L})$. Therefore, we analysed the results based on $25(\mathrm{OH}) \mathrm{D}$ response (table 3$)$. There was a greater improvement in total SRS score in those with increased 25(OH)D. In contrast, there was a greater improvement in total $\mathrm{ABC}$ and $\mathrm{ABC}$ subscales in those with decreased $25(\mathrm{OH}) \mathrm{D}$. The three children who had no change in $25(\mathrm{OH}) \mathrm{D}$ levels also displayed improvements on ABC, SRS and DD-CGAS. 
Downloaded from http://adc.bmj.com/ on June 17, 2017 - Published by group.bmj.com

\section{Original article}

Table 2 Subjective and biochemical results before and after the trial

\begin{tabular}{|c|c|c|c|c|c|c|c|}
\hline \multirow[b]{2}{*}{$\mathbf{n}$} & \multicolumn{3}{|l|}{ Placebo } & \multicolumn{3}{|c|}{ Vitamin D } & \multirow[t]{2}{*}{$\mathrm{p}$ Value* } \\
\hline & 20 & & & 18 & & & \\
\hline & Pre & Post & $\Delta$ & Pre & Post & $\Delta$ & \\
\hline \multicolumn{8}{|l|}{$A B C$} \\
\hline Irritability (0-45) & 14.1 & 9 & -5.1 & 14.8 & 12.3 & -3.5 & 0.45 \\
\hline Lethargy (0-48) & 10.2 & 5.6 & -4.6 & 13.4 & 10.2 & -3.2 & 0.88 \\
\hline Stereotypical behaviour (0-21) & 7.8 & 4.8 & -3 & 6.7 & 5.9 & -0.8 & 0.28 \\
\hline Hyperactivity (0-48) & 18.6 & 13.3 & -5.3 & 19.2 & 15.7 & -3.5 & 0.63 \\
\hline Inappropriate speech (0-12) & 5.4 & 2.9 & -2.5 & 4.2 & 4.1 & -0.1 & 0.08 \\
\hline Total & 55.9 & 35.5 & -20.4 & 58.3 & 48.2 & -10.1 & 0.2 \\
\hline \multicolumn{8}{|l|}{ SRS } \\
\hline Total (0-260) & 150.3 & 137.6 & -12.7 & 149.1 & 124.8 & -24.6 & 0.48 \\
\hline \multicolumn{8}{|l|}{ DD-CGAS } \\
\hline Self-care $(0-100)$ & 47 & 54.5 & 7.5 & 39.1 & 59.4 & 20.3 & 0.02 \\
\hline Communication (0-100) & 46.5 & 57.5 & 11 & 40.8 & 52.6 & 11.8 & 0.6 \\
\hline Social behaviour (0-100) & 50.5 & 56.3 & 5.8 & 40.6 & 55.6 & 5 & 0.38 \\
\hline School/academic (0-100) & 46.5 & 59.5 & 13 & 43.2 & 51.2 & 8 & 0.24 \\
\hline \multicolumn{8}{|l|}{ Biochemistry } \\
\hline $\mathrm{CRP}(\mathrm{mg} / \mathrm{L})$ & 2.7 & 1.5 & -1.2 & 1.1 & 1.3 & 0.2 & 0.4 \\
\hline Neutrophil:lymphocyte & 1.1 & 1.2 & 0.1 & 1 & 1.3 & 0.3 & 0.58 \\
\hline $\mathrm{Ca}^{2+}(\mathrm{mmol} / \mathrm{L})$ & 2.3 & 2.33 & 0.03 & 2.3 & 2.3 & 0 & 0.26 \\
\hline $25(\mathrm{OH}) \mathrm{D}(\mathrm{nmol} / \mathrm{L})$ & 51.7 & 50.6 & -1.1 & 58.5 & 86.1 & 27.6 & 0.0016 \\
\hline
\end{tabular}

${ }^{*} \mathrm{p}$ Values derived from unpaired t-tests.

25(OH)D, 25-hydroxyvitamin D; ABC, Aberrant Behaviour Checklist; Ca ${ }^{2+}$, albumin-corrected calcium; CRP, C reactive protein; DD-CGAS, Developmental Disabilities-Children's Global Assessment Scale; SRS, Social Responsiveness Scale.

Because it has been hypothesised that vitamin D supplementation may be most beneficial regarding ASD in early life, ${ }^{26}$

\begin{tabular}{|c|c|c|c|}
\hline & $\begin{array}{l}\text { Decreased } \\
25(\mathrm{OH}) \mathrm{D}\end{array}$ & $\begin{array}{l}\text { Unchanged } \\
\text { 25(OH)D }\end{array}$ & $\begin{array}{l}\text { Increased } \\
\text { 25(OH)D }\end{array}$ \\
\hline $\mathrm{n}$ & 10 & 3 & 24 \\
\hline PL allocation & 9 & 2 & 9 \\
\hline $\mathrm{D}_{3}$ allocation & 1 & 1 & 15 \\
\hline \multicolumn{4}{|l|}{$A B C$} \\
\hline Irritability (0-45) & -38 & 2 & -4 \\
\hline Lethargy (0-48) & -56 & -5 & -4 \\
\hline Stereotypical behaviour (0-21) & -59 & -2 & -2 \\
\hline Hyperactivity (0-48) & -42 & -4 & -3.5 \\
\hline Inappropriate speech (0-12) & -53 & 0 & -1 \\
\hline Total (0-174) & -49 & -9 & -13 \\
\hline \multicolumn{4}{|l|}{ SRS } \\
\hline Total & -14 & -1 & -23 \\
\hline \multicolumn{4}{|l|}{ DD-CGAS } \\
\hline Self-care (0-100) & 12 & 17 & 14 \\
\hline Communication (0-100) & 25 & 17 & 10 \\
\hline Social behaviour (0-100) & 20.7 & -18 & 10 \\
\hline School/academic (0-100) & 27 & 7 & 11 \\
\hline \multicolumn{4}{|l|}{ Biochemistry } \\
\hline $\mathrm{CRP}(\mathrm{mg} / \mathrm{L})$ & 10 & -9 & 0.1 \\
\hline Neutrophil:lymphocyte & 0.2 & -1 & 0.1 \\
\hline $\mathrm{Ca}^{2+}(\mathrm{mmol} / \mathrm{L})$ & 2 & -0.01 & 0.1 \\
\hline $25(\mathrm{OH}) \mathrm{D}(\mathrm{nmol} / \mathrm{L})$ & -37 & 0 & 25 \\
\hline
\end{tabular}

25(OH)D, 25-hydroxyvitamin D; ABC, Aberrant Behaviour Checklist; $\mathrm{Ca}^{2+}$, albumincorrected calcium; CRP, C reactive protein; DD-CGAS, Developmental DisabilitiesChildren's Global Assessment Scale; PL, placebo; SRS, Social Responsiveness Scale.
27 we analysed results based on age. Although irritability improved significantly more in those $<6$ years compared with those $>6$ years $(p=0.04)$, there were no other significant differences, including stereotypical behaviour (primary endpoint).

Table 4 presents the correlation coefficients between $\mathrm{ABC}$, SRS and DD-CGAS parameters versus $25(\mathrm{OH}) \mathrm{D}$ at both baseline and follow-up. We observed only a single significant correlation

\begin{tabular}{lcc}
\hline \multicolumn{2}{l}{ Table 4} & \multicolumn{2}{c}{ Correlations between ASD parameters and 25(OH)D } \\
\hline & Baseline & Follow-up \\
\hline ABC & & \\
Irritability & 0.29 & 0.27 \\
Lethargy & 0.12 & 0.04 \\
Stereotypical behaviour & 0.18 & 0.14 \\
Hyperactivity & $0.36^{*}$ & 0.19 \\
Inappropriate speech & 0.17 & 0.14 \\
Total & 0.3 & 0.2 \\
SRS & & \\
Total & 0.2 & 0.04 \\
DD-CGAS & & \\
Self-care (0-100) & 0.006 & 0.139 \\
Communication & -0.28 & -0.06 \\
Social behaviour & -0.003 & 0.12 \\
School/academic & -0.16 & 0.06 \\
\hline
\end{tabular}

*Significant $(\mathrm{p}=0.018)$

25(OH)D, 25-hydroxyvitamin D; ABC, Aberrant Behaviour Checklist; DD-CGAS, Developmental Disabilities—Children's Global Assessment Scale; SRS, Social Responsiveness Scale. 
with baseline $25(\mathrm{OH}) \mathrm{D}$ and no significant relationships with follow-up 25(OH)D.

\section{DISCUSSION}

We present one of the first randomised, double-blind, placebo-controlled trials of vitamin D in ASD. We investigated the effect of vitamin $\mathrm{D}_{3}$ supplementation (2000 IU/day) for 20 weeks among a small sample of urban, mostly Caucasian children with clinician-diagnosed ASD at high latitude over winter season. In contrast to most ${ }^{112627}$ but not all previous reports, ${ }^{21}$ there was no difference between VDD and VDS groups regarding ASD parameters at baseline. There was a significant increase in vitamin $\mathrm{D}$ status in the $\mathrm{D}_{3}$ group. However, there was no effect on the prespecified primary endpoint: stereotypical behaviour subscale from $\mathrm{ABC}$.

A significant improvement was observed in a single, exploratory outcome (self-care score) with vitamin D supplementation. A non-significant improvement was observed in another single, exploratory outcome (decreased inappropriate speech) in the PL group. These contradictory observations are likely stochastic or statistical artefact. There were no other observed differences between groups.

In the vitamin $\mathrm{D}$ arm, 25(OH)D decreased in a single child and did not change in a second child. Although reported compliance with the supplements was high, this could nevertheless be explained by non-compliance (we did not objectively measure compliance). Other explanations include measurement error or absorption issues. We cannot rule out an absorption/metabolic issue with vitamin $\mathrm{D}$ which is supported by a recent small study where $25(\mathrm{OH}) \mathrm{D}$ was significantly lower in 42 ASD children compared with 40 typically developing children $(p<0.001)$ despite similar sun exposure and oral intake. ${ }^{33}$ Furthermore, despite conducting this trial at high latitude over the winter season and the lack of change in VIDSun scores, $25(\mathrm{OH})$ remained constant in two children and actually increased in nine children in the PL group ( +1 to $+45 \mathrm{nmol} / \mathrm{L})$. This could possibly reflect commencement of non-trial vitamin $\mathrm{D}$ supplementation or skin photosynthesis of vitamin D, since follow-up occurred in mid-late spring. Based on these observations, we further analysed results based on $25(\mathrm{OH}) \mathrm{D}$ response, which revealed inconsistent results. We also conducted regression analysis, which revealed only a single significant relationship (out of 22), again suggesting a stochastic or statistical artefact. Collectively, our results suggest that there was no benefit of vitamin $\mathrm{D}_{3}$ supplementation in ASD compared with placebo. Furthermore, improvements in the children whose $25(\mathrm{OH}) \mathrm{D}$ level either decreased or did not change suggest a significant placebo effect. The placebo effects pose significant challenges in ASD regarding reliable detection of a treatment response. A recent study simulated a clinical trial with baseline and endpoint assessments but no treatment, yet caregivers reported ABC and SRS improvements. ${ }^{34}$

In addition to multiple reports of inadequate vitamin $\mathrm{D}$ intake $^{8-11}$ and/or vitamin D status ${ }^{11-21}$ in ASD, detailed in vitro and in silico work has demonstrated that relevant genes (eg, THP2 gene) and brain hormones (serotonin, oxytocin and vasopressin) are directly regulated by calcitriol, also known as 1,25-dihydroxyvitamin D3 (1,25D), ${ }^{23} 3536$ implying that VDD may have a role in ASD. Furthermore, an early report of vitamin D supplementation providing protective and restorative effects on ASD features in rat pups ${ }^{24}$ increased interest in the therapeutic potential of vitamin D for ASD. This was followed by a case study reporting improvement of core ASD symptoms following $150000 \mathrm{IU} /$ month for 2 months + $400 \mathrm{IU} /$ day in a 32 month-old
Chinese boy with VDD and ASD. ${ }^{25}$ Subsequently, two openlabel studies were published. An Egyptian study reported that 67 of 83 VDD children with ASD (81\%) had improved ABC and childhood autism rating scale following vitamin $\mathrm{D}_{3}$ supplementation (300 IU/day/kg of body weight) for 12 weeks. $^{26}$ Another open-label study from China assessed 37 VDD children before and after monthly intramuscular vitamin $\mathrm{D}_{3}$ (150000 IU) and daily oral vitamin $\mathrm{D}_{3}$ (400 IU). Total $\mathrm{ABC}$ and SRS scores were reduced significantly after 12 weeks. ${ }^{27}$ Additionally, a very recent, double-blind, randomised, placebo-controlled trial consisted of 109 ASD children (3-10 years) randomised to daily vitamin D (300 IU/kg of body weight but $\leq 5000 \mathrm{IU})$ or placebo for 4 months. Vitamin D supplementation significantly improved ABC, SRS, childhood autism rating scale and Autism Treatment Evaluation Checklist scores. ${ }^{28}$ Although there were many similarities between our trial and this other trial, there are several notable differences. Our cohort were older (mean age 7.4 vs 5.4 years), had lower $\mathrm{ABC}$ scores (and perhaps milder ASD) and had lower baseline 25(OH)D (54.2 versus $66 \mathrm{nmol} / \mathrm{L})$. Furthermore, the change in $25(\mathrm{OH}) \mathrm{D}$ was lower in our trial $(+25$ versus $+49 \mathrm{nmol} / \mathrm{L})$ resulting in a much lower $25(\mathrm{OH}) \mathrm{D}$ level at follow-up (83.8 versus $114.8 \mathrm{nmol} / \mathrm{L})$.

\section{Trial strengths}

We used the gold standard study design and assessed a combination of widely used subjective assessments and biochemical markers. The PL and vitamin D groups were well matched at baseline with no significant differences in demographics, including $25(\mathrm{OH}) \mathrm{D}$.

Vitamin D trials can be influenced by a number of factors, including fluctuations in sun exposure, variable quality of vitamin $\mathrm{D}$ assays, compliance with the intervention and provision of inadequate vitamin $\mathrm{D}$ supplementation doses. To overcome these factors, we conducted this trial over the winter season at high latitude when vitamin D photosynthesis is minimal. Although we purposely did not restrict non-protocol dietary or supplemental vitamin D intake, we did ask that such behaviours were not altered during the trial. Vitamin D behaviours were similar in both groups throughout the trial. We used the current gold standard assay for total 25(OH)D. Reported supplement compliance was high. We used a moderate-to-high dose of vitamin $\mathrm{D}_{3}(2000$ IU/day) Finally, comorbidities and medication use were rare in both groups. Furthermore, there was no change in non-trial medication/therapy/supplementation.

\section{Trial limitations}

Limitations of our study include the relatively small number of subjects. We used fixed vitamin D dosing, but it may be more appropriate to titrate vitamin D dosing based on baseline 25(OH)D levels and/or body size. ${ }^{24} 2628$

We did not selectively recruit VDD children. However, any detrimental effect of low 25(OH)D may be most apparent when comparing VDD with VDS. In this trial, mean baseline $25(\mathrm{OH})$ $\mathrm{D}$ was $54.2 \mathrm{nmol} / \mathrm{L}$ (range: $15-101 \mathrm{nmol} / \mathrm{L}$ ). Only 17 children were VDD (40\%). However, previous open-label studies ${ }^{2627}$ and a randomised controlled trial also included subjects who were not VDD ${ }^{28}$ which all demonstrated benefit of vitamin D supplementation.

Although $25(\mathrm{OH}) \mathrm{D}$ is considered the best circulating biomarker of vitamin D status, there are many important metabolites and intermediates in the vitamin D metabolic pathway. For example, paternal ${ }^{37}$ and individual ${ }^{38} 39$ vitamin D receptor (VDR) polymorphisms have been associated with increased ASD 
risk. We did not measure levels of vitamin D-binding protein, VDR or calcitriol $(1,25 \mathrm{D})$ which may have provided interesting insight here.

Stereotypical behaviour was selected as the primary outcome measure based on a single, open-label study reported prior to the design of this study. ${ }^{26}$ To our knowledge, there are no mechanisms by which vitamin D could specifically improve stereotypical behaviour. However, another recent trial also reported a significant improvement in stereotypical behaviour in ASD after vitamin D supplementation. $^{28}$

It is possible that we studied children who were too old to gain neurodevelopmental benefit from vitamin D supplementation. Furthermore, vitamin D supplementation has been suggested to have primary prevention potential regarding ASD. ${ }^{38-44}$ Furthermore, vitamin D supplementation has been suggested to have primary prevention potential regarding ASD. ${ }^{38} 43$ Although we analysed results based on age (ie, $<6$ vs 6 years), vitamin D treatment effects have been reported to be more pronounced in younger children $\left(<3\right.$ years) with $\mathrm{ASD}^{27}$ leading to the suggestion that vitamin D supplementation should start in early infancy or during gestation. ${ }^{26} 27$ 39-44 In this context, it is possible that there is a window of opportunity for adequate $25(\mathrm{OH}) \mathrm{D}$ to provide neuroprotection and that we included older children in whom neuronal networks are established and therefore less likely to benefit from supplementation (mean age in vitamin D group 7.9 years).

Finally, it is possible that a higher dose of vitamin D would produce a greater change in both $25(\mathrm{OH}) \mathrm{D}$ and ASD behaviour. Some reports have demonstrated selective success with vitamin D supplementation when $25(\mathrm{OH}) \mathrm{D}$ exceeds $100 \mathrm{nmol} / \mathrm{L}^{26}$ ${ }^{28}$ In this study, only five children $(13 \%)$ obtained a $25(\mathrm{OH})$ $\mathrm{D}>100 \mathrm{nmol} / \mathrm{L}$.

\section{CONCLUSIONS}

Our results do not support supplementary vitamin D for children with ASD. Considering preliminary interventional studies of 8-16 weeks ${ }^{26-28}$ as well as the extent of vitamin D deficiency in ASD and the low cost and high benefit to risk ratio of vitamin D supplementation, larger and preferably longer trials, perhaps focusing on primary prevention and/or younger children as well as relevant mechanisms and optimal dose/duration of supplementation/25(OH)D levels with ASD, are warranted.

Acknowledgements This trial was sponsored by the National Children's Hospital Foundation. We wish to acknowledge the valuable contribution of Codruta Sudrijan regarding scoring of ASD assessments and of Eleisa Aheron regarding statistical methods. We also wish to thank the nursing staff at the National Children's Hospital including Stephanie Kelly and particularly Tara Larkin and Exelma Omallao. Finally, we wish to thank the laboratory personnel at the TCD Research Lab for assistance and use of facilities: Julie Renwick, Victoria McEneaney and Elaine O' Mullane.

Contributors CPK conceptualised and designed the study and data collection instruments, coordinated and supervised data collection, carried out the initial analyses, drafted the initial manuscript and approved the final manuscript as submitted. CP reviewed, coordinated and supervised data collection; revised the manuscript and approved the final manuscript as submitted. LG designed the data collection instruments and approved the final manuscript as submitted. DC conceptualised and designed the study, carried out the initial analyses and approved the final manuscript as submitted.

Funding This trial was supported by funding from the National Children's Hospital Foundation, Ireland. The funding body had no involvement instudy design, data collection, analysis or interpretation.

Competing interests None declared.

Patient consent Guardian consent obtained.

Ethics approval Research Ethics Committee of the National Children's Hospital.

Provenance and peer review Not commissioned; externally peer reviewed. (c) Article author(s) (or their employer(s) unless otherwise stated in the text of the article) 2017. All rights reserved. No commercial use is permitted unless otherwise expressly granted.

\section{REFERENCES}

1 Newschaffer CJ, Falb MD, Gurney JG. National autism prevalence trends from United States special education data. Pediatrics 2005; 115:e277-82.

2 Kinney DK, Barch DH, Chayka B, et al. Environmental risk factors for autism: do they help cause de novo genetic mutations that contribute to the disorder? Med Hypotheses 2010;74:102-6.

3 Holick MF. Vitamin D deficiency. N Engl J Med 2007;357:266-81.

4 Cannell JJ. Autism, will vitamin D treat core symptoms? Med Hypotheses 2013;81:195-8.

5 Cannell JJ, Grant WB. What is the role of vitamin D in autism? Dermatoendocrinol 2013;5:199-204.

6 Mazahery $\mathrm{H}$, Camargo CA, Conlon C, et al. Vitamin D and autism spectrum disorder: a literature review. Nutrients 2016;8:236

7 Ali A, Cui X, Eyles D. Developmental vitamin D deficiency and autism: Putative pathogenic mechanisms. J Steroid Biochem Mol Biol 2016 (Epub ahead of print: 24 Dec 2016).

8 Herndon AC, DiGuiseppi C, Johnson SL, et al. Does nutritional intake differ between children with autism spectrum disorders and children with typical development? J Autism Dev Disord 2009;39:212-22.

9 Hyman SL, Stewart PA, Schmidt B, et al. Nutrient intake from food in children with autism. Pediatrics 2012;130 Suppl 2(Suppl 2):S145-53.

10 Graf-Myles J, Farmer C, Thurm A, et al. Dietary adequacy of children with autism compared with controls and the impact of restricted diet. J Dev Behav Pediatr 2013:34:449-59.

11 Meguid N, Anwar M, Zaki S, et al. Dietary patterns of children with autism spectrum disorder: a study based in Egypt. Open Access Maced J Med Sci 2015;3:262-7.

12 Meguid NA, Hashish AF, Anwar M, et al. Reduced serum levels of 25-hydroxy and 1,25-dihydroxy vitamin D in Egyptian children with autism. J Altern Complement Med 2010;16:641-5.

13 Molloy CA, Kalkwarf HJ, Manning-Courtney P, et al. Plasma 25(OH)D concentration in children with autism spectrum disorder. Dev Med Child Neurol 2010;52:969-71.

14 Tostes MH, Polonini HC, Gattaz WF, et al. Low serum levels of 25-hydroxyvitamin D (25-OHD) in children with autism. Trends Psychiatry Psychother 2012;34:161-3.

15 Mostafa GA, Al-Ayadhi LY. Reduced serum concentrations of 25-hydroxy vitamin D in children with autism: relation to autoimmunity. J Neuroinflammation 2012;9:201.

16 Bener A, Khattab AO, Al-Dabbagh MM. Is high prevalence of Vitamin D deficiency evidence for autism disorder?: In a highly endogamous population. J Pediatr Neurosci 2014;9:227-33.

17 Gong ZL, Luo CM, Wang L, et al. Serum 25-hydroxyvitamin D levels in chinese children with autism spectrum disorders. Neuroreport 2014;25:23-7.

18 Kočovská E, Andorsdóttir G, Weihe P, et al. Vitamin D in the general population of young adults with autism in the Faroe islands. J Autism Dev Disord 2014;44:2996-3005.

19 Esparham AE, Smith T, Belmont JM, et al. Nutritional and metabolic biomarkers in autism spectrum disorders: an exploratory study. Integr Med 2015;14:40-53.

20 Bala KA, Doğan M, Kaba S, et al. Hormone disorder and vitamin deficiency in attention deficit hyperactivity disorder (ADHD) and autism spectrum disorders (ASDs). J Pediatr Endocrinol Metab 2016;29:1077-82.

21 Liu X, Liu J, Xiong X, et al. Correlation between nutrition and symptoms: nutritional survey of children with autism spectrum disorder in Chongqing, China. Nutrients 2016;8:294.

22 Wang T, Shan L, Du L, et al. Serum concentration of 25-hydroxyvitamin D in autism spectrum disorder: a systematic review and meta-analysis. Eur Child Adolesc Psychiatry 2016;25:341-50.

23 Patrick RP, Ames BN. Vitamin D hormone regulates serotonin synthesis. Part 1: relevance for autism. Faseb J 2014;28:2398-413.

24 Alfawaz HA, Bhat RS, Al-Ayadhi L, et al. Protective and restorative potency of vitamin $D$ on persistent biochemical autistic features induced in propionic acid-intoxicated rat pups. BMC Complement Altern Med 2014;14:416.

25 Jia F, Wang B, Shan L, et al. Core symptoms of autism improved after vitamin D supplementation. Pediatrics 2015;135:e196-8.

26 Saad K, Abdel-Rahman AA, Elserogy YM, et al. Vitamin D status in autism spectrum disorders and the efficacy of vitamin D supplementation in autistic children. Nutr Neurosci 2016;19:346-51.

27 Feng J, Shan L, Du L, et al. Clinical improvement following vitamin D3 supplementation in autism spectrum disorder. Nutr Neurosci 2017;20:284-90.

28 Saad K, Abdel-Rahman AA, Elserogy YM, et al. Randomized controlled trial of vitamin D supplementation in children with autism spectrum disorder. J Child Psychol Psychiatry 2016 (Epub ahead of print: 21 Nov 2016).

29 Nabak AC, Johnson RE, Keuler NS, et al. Can a questionnaire predict vitamin D status in postmenopausal women? Public Health Nutr 2014;17:739-46.

30 Kaat AJ, Lecavalier L, Aman MG. Validity of the aberrant behavior checklist in children with autism spectrum disorder. J Autism Dev Disord 2014;44:1103-16. 
31 Kerley CP, Hutchinson K, Cormican L, et al. Vitamin D3 for uncontrolled childhood asthma: a pilot study. Pediatr Allergy Immunol 2016;27:404-12

32 Ross AC, Manson JE, Abrams SA, et al. The 2011 report on dietary reference intakes for calcium and vitamin D from the Institute of Medicine: what clinicians need to know. J Clin Endocrinol Metab 2011;96:53-8.

33 Fahmy F, Sabri NA, El Hamamsy MH, et al. Vitamin D intake and sun exposure in autistic children. Internationa J Pharm Sci Res 2016;7:1043-9.

34 Jones RM, Carberry C, Hamo A, et al. Placebo-like response in absence of treatment in children with Autism. Autism Res 2017 (Epub ahead of print: 12 Apr 2017).

35 Siniscalco D, Bradstreet JJ, Cirillo A, et al. The in vitro GcMAF effects on endocannabinoid system transcriptionomics, receptor formation, and cell activity of autism-derived macrophages. J Neuroinflammation 2014;11:78.

36 Kaneko I, Sabir MS, Dussik CM, et al. 1,25-Dihydroxyvitamin D regulates expression of the tryptophan hydroxylase 2 and leptin genes: implication for behavioral influences of vitamin D. Faseb J 2015;29:4023-35

37 Schmidt RJ, Hansen RL, Hartiala J, et al. Selected vitamin D metabolic gene variants and risk for autism spectrum disorder in the CHARGE Study. Early Hum Dev 2015:91:483-9.
38 Coşkun S, Şimşek Ş, Camkurt MA, et al. Association of polymorphisms in the vitamin D receptor gene and serum 25-hydroxyvitamin D levels in children with autism spectrum disorder. Gene 2016;588:109-14.

39 Grant WB, Soles CM. Epidemiologic evidence supporting the role of maternal vitamin $D$ deficiency as a risk factor for the development of infantile autism. Dermatoendocrinol 2009;1:223-8.

40 Whitehouse AJ, Holt BJ, Serralha M, et al. Maternal vitamin D levels and the autism phenotype among offspring. J Autism Dev Disord 2013;43:1495-504.

41 Fernell E, Bejerot $\mathrm{S}$, Westerlund J, et al. Autism spectrum disorder and low vitamin D at birth: a sibling control study. Mol Autism 2015:6:3

42 Chen J, Xin K, Wei J, et al. Lower maternal serum 25(OH) D in first trimester associated with higher autism risk in chinese offspring. J Psychosom Res 2016;89:98-101.

43 Magnusson C, Lundberg M, Lee BK, et al. Maternal vitamin D deficiency and the risk of autism spectrum disorders: population-based study. BJPsych Open 2016:2:170-2.

44 Stubbs G, Henley K, Green J. Autism: will vitamin D supplementation during pregnancy and early childhood reduce the recurrence rate of autism in newborn siblings? Med Hypotheses 2016;88:74-8. 


\section{ADC Lack of effect of vitamin $D_{3}$ supplementation in autism: a 20-week, placebo-controlled RCT}

Conor P Kerley, Clare Power, Louise Gallagher and David Coghlan

Arch Dis Child published online June 16, 2017

Updated information and services can be found at:

http://adc.bmj.com/content/early/2017/06/15/archdischild-2017-31278

3

\section{These include:}

References This article cites 41 articles, 4 of which you can access for free at: http://adc.bmj.com/content/early/2017/06/15/archdischild-2017-31278 3\#BIBL

Email alerting Receive free email alerts when new articles cite this article. Sign up in the service box at the top right corner of the online article.

\section{Notes}

To request permissions go to:

http://group.bmj.com/group/rights-licensing/permissions

To order reprints go to:

http://journals.bmj.com/cgi/reprintform

To subscribe to BMJ go to:

http://group.bmj.com/subscribe/ 